\title{
INTRA-GENERATION INBREEDING EFFECTS IN A POULTRY FLOCK SELECTED FOR EGG PRODUCTION
}

\author{
G. TEBB * \\ Department of Poultry Husbandry, University of California, Berkeley
}

\section{INTRODUCTION}

Received 4.xii. 57

IT is inevitable that the levels of inbreeding within a selected closed flock should gradually rise above those of the initial stock. This effect is, of course, due to the finite size of the population, and to the fact that the genotypes selected represent only a part of the total gene pool of a generation. If, however, the flock is sufficiently large, and care is taken to restrict the mating together of closely related birds, the increased inbreeding may not be clearly detrimental. In poultry, egg production, fertility and hatchability of eggs, and vigour of offspring, may not necessarily show unequivocal decreases as the result of inbreeding. Indeed, these components of fitness may actually rise as a result of selection. Nevertheless, even if this is true it may still be possible, by appropriate statistical analysis, to demonstrate detrimental effects of inbreeding should they exist.

That inbreeding, generally speaking, has an adverse effect on many traits is well known. Jull (I933) and Stephenson et al. (I953) quote the works of a number of authors who attest to this in poultry. But almost all reports in the literature concern continuous close mating programmes, such as those of brother by half- or full-sister, and, consequently, a high rate of increase in the levels of inbreeding. The result, in these cases, is often that fitness is so greatly reduced that the existence of the line is in jeopardy. No studies of the effects of inbreeding when the rate of increase in the inbreeding levels is minimal for the size of the flock, when that size itself is relatively large, and when selection for some component of fitness has been effective, have apparently been attempted. But these are the effects which are likely to be operative in most cases of selection in closed flocks, and would therefore be pertinent to many aspects of selection problems and, indeed, to the future of closed flock breeding in general. An analysis of some of the effects has, therefore, been carried out, and is reported here.

\section{MATERIALS AND METHODS}

The University of California maintains a Single Comb White Leghorn flock which has been selected for egg production in each generation since its inception in 19.32. Its history has been given in detail by Lerner (1950). Lerner and Hazel

* On leave from the Poultry Research Centre, Edinburgh, Scotland, to which correspondence should now be addressed. 
(1947) have tersely presented the essential features of the breeding plan, the following aspects of which are most relevant for the purposes of this study :

(1) Occasional outcrosses were made in the early years of the flock formation, the flock being closed after $194^{1}$;

(2) The size of the flock varied from 400 to 700 pullets each year from approximately I I sires and 85 dams, with an exception of 260 pullets in 1944 ;

(3) Mating of closely related individuals was consciously avoided.

Lerner and Hazel note an average increase of $2 \cdot I$ per cent. in the inbreeding coefficient per generation, or of about I per cent. per year when the average combined sire and dam inter-generation interval is taken into account.

The study reported here concerns data accumulated over a period of 18 years, from 1932 to 1949 and, in particular, after closure of the flock in $194 \mathrm{I}$. In general, linear regression coefficients relating egg production (and its various components) and increases in inbreeding have been investigated. All inbreeding coefficients (Wright's $F$ ) were computed from the base year 1925. Since selection led to increasing egg production itself, even though this increase was accompanied over the generations by slowly rising coefficients of inbreeding, the analyses have been made on an intra-generation basis. Since in any one year there is no reason to expect a systematic relationship between inbreeding and selection pressure applied in the past, this method should largely eliminate bias which would otherwise come about from the parallel increase in $F$ and in the characteristics under selection. It should be noted that, from studies of the relationship between family size and inbreeding (reported below), it was thought unnecessary, except in one case, to use any form of weighting in regression calculations.

\section{RESULTS}

I. Number of birds. Although members of each group of full sisters have an identical coefficient of inbreeding, the dam families in each generation show a range of values. At the time of a preliminary report on this study (Tebb, I957) no evidence had been found for any relationship between pullet number and computed $F$. However, analyses on the data of earlier years show this lack of relationship applied only after closure of the flock.

Table I, column (a), gives the linear regression coefficient of family size (pullet offspring only) against family $F$, for each year from $193^{2}$ to 1949 . Twelve years show negative coefficients, but only one (1938, with a value of -0.195 ) reached the 5 per cent. level of significance.

Table 2 shows the regressions pooled within three arbitrary subperiods and for the whole period. It should be noted that the occasionally significant $F$-test values for between years indicate that the regressions for different years within sub-periods are not necessarily the same. The regression for each group of years may therefore be viewed as an estimate of a weighted average of the regressions of the individual years, the weights being the within-years degrees of freedom for error, implied in the table. A significant $F$-test value for the pooled regression, based on the error mean square, indicates that this weighted average regression for the particular years is different from zero. An implicit assumption here is that the error variances are the same in all years. 


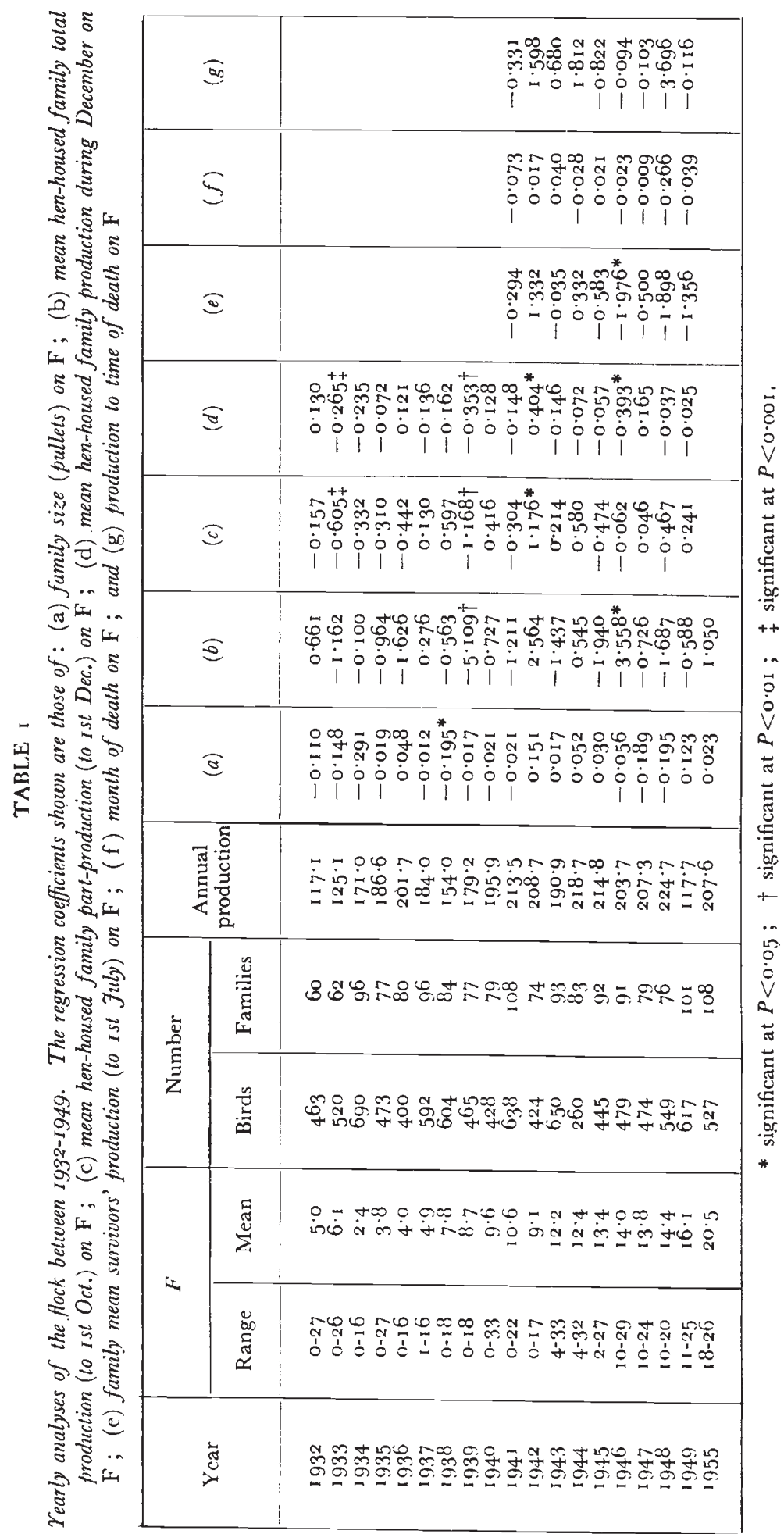


From 1932-37, the mean annual coefficient of inbreeding $(F)$ rose from $2 \cdot 40$ to $6 \cdot 12$, and the pooled regression of family size (linear) of -0.089 is significant at the 5 per,cent. level. From 1938-42 F rose to 10.59 , and the pooled regression of $-0 \cdot 043$ is also significant at the 5 per cent. level. From $1943-49 F$ rose to $16 \cdot$ I I, and the pooled

TABLE 2

Analyses of the pooled yearly regressions, on computed F, of (a) family size (pullets), (b) family mean total production (to Ist Oct.), (c) family mean part-production (to Ist Dec.), (d) family mean production during December. The three sub-periods and the total period are analysed separately

\begin{tabular}{|c|c|c|c|c|c|c|}
\hline \multirow{2}{*}{ Period } & \multicolumn{2}{|c|}{$\begin{array}{l}\text { Pooled within-year } \\
\text { regression }\end{array}$} & \multicolumn{2}{|c|}{$\begin{array}{l}\text { Yearly regression } \\
\text { differences }\end{array}$} & \multicolumn{2}{|c|}{ Error } \\
\hline & Value & M.S. & d.f. & M.S. & d.f. & M.S. \\
\hline $\begin{aligned} 1932-37 & (a) \\
& (b) \\
& (c) \\
& (d)\end{aligned}$ & $\begin{array}{l}-0.089 \\
-0.618 \\
-0.335 \\
-0.103\end{array}$ & $\begin{array}{r}7^{*} \\
374^{*} \\
\text { I } 105 \dagger \\
\text { I0 }\end{array}$ & $\begin{array}{l}5 \\
5 \\
5 \\
5\end{array}$ & $\begin{array}{r}\text { I } 8 \\
\text { I } 66 \\
\text { I } 08 \\
46\end{array}$ & $\begin{array}{l}459 \\
459 \\
459 \\
459\end{array}$ & $\begin{array}{r}12 \\
1969 \\
158 \\
25\end{array}$ \\
\hline $\begin{aligned} \text { I } 938-42 & (a) \\
& (b) \\
(c) & (d)\end{aligned}$ & $\begin{array}{r}-0.043 \\
-\mathrm{I} .157 \\
0.033 \\
-0.080\end{array}$ & $\begin{array}{r}5 \mathrm{I} * \\
\mathrm{I} \mathrm{I}, 202 * \\
9 \\
54\end{array}$ & $\begin{array}{l}4 \\
4 \\
4 \\
4\end{array}$ & $\begin{array}{r}\text { Io } \\
6837^{*} \\
906 \dagger \\
85^{*}\end{array}$ & $\begin{array}{l}412 \\
412 \\
412 \\
412\end{array}$ & $\begin{array}{r}10 \\
284^{8} \\
219 \\
27\end{array}$ \\
\hline $\begin{array}{r}\text { I } 943-49(a) \\
(b) \\
(c) \\
(d)\end{array}$ & $\begin{array}{r}0.005 \\
-1.330 \\
0.037 \\
-0.098\end{array}$ & $\begin{array}{c}\text { I } 3,195^{*} \\
10 \\
72\end{array}$ & $\begin{array}{l}6 \\
6 \\
6 \\
6\end{array}$ & $\begin{array}{r}\text { IO } \\
1847 \\
171 \\
24\end{array}$ & $\begin{array}{l}601 \\
601 \\
601 \\
601\end{array}$ & $\begin{array}{r}78 \\
2657 \\
167 \\
23\end{array}$ \\
\hline $\begin{array}{r}\text { I } 932-49 \\
(a) \\
(c) \\
(d) \\
(d)\end{array}$ & $\begin{array}{l}-0.047 \\
-1 \cdot 001 \\
-0.107 \\
-0.094\end{array}$ & $\begin{array}{c}56 * \\
25.689 \\
292 \\
228 \dagger\end{array}$ & $\begin{array}{l}17 \\
17 \\
17 \\
\text { I } 7\end{array}$ & $\begin{array}{r}\text { I } 6 \\
274^{8} \\
354^{*} \\
42^{*}\end{array}$ & $\begin{array}{l}1472 \\
1472 \\
1472 \\
1472\end{array}$ & $\begin{array}{r}10 \\
2496 \\
179 \\
25\end{array}$ \\
\hline
\end{tabular}

regression is positive $(0.005)$ but not significant. When all years are combined, the regression coefficient of -0.047 is also significant at the 5 per cent. level. In no period is the mean square of the differences between annual regressions significant.

Table I, column $(a)$, includes the coefficient for I955, and this is slightly positive but statistically insignificant. Thus it seems that whatever the dependence of family size on inbreeding has been, it apparently ceased after closure of the flock. In view of the objections to weighting, of the relatively small ranges in fanily size, and of the independence between family size and $F$, in the later stages, unweighted regressions have been used chiefly but not entirely.

2. Annual production index. Table I gives essential data pertaining to the flock in each year. Differences in some of the earlier years from similar data in Lerner and Dempster (I95I) are due to differential treatment of floor-layers in the two cases. 
Table I, column $(b)$, shows the linear regression coefficients of mean family production on $F$. The production figures used were those from beginning of lay to October in the first laying year, and the family means were based on the numbers of pullets initially banded, i.e. the production index (or hen-housed average) was used. There are 4 positive, and 14 negative coefficients. In only two years are these coefficients statistically significant: in $1939(-5 \cdot 109)$ at the I per cent. level, and in $1946(-3.558)$ at the 5 per cent. level.

Table 2 , line $(b)$, gives the pooled analyses for the three sub-periods and for all years together. From 1932-37, neither the joint regression $(-0.6 \mathrm{I} 8)$ nor the differences between annual regressions are significant. Both the joint regression $(-\mathrm{I} \cdot \mathrm{I} 57)$ and the annual differences are significant, at the 5 per cent. level, from I 938-42. The joint regression $\left(-\mathrm{I} \cdot 33^{0}\right)$ is alone significant, at the 5 per cent. level, from I943-49. Finally, the overall regression for all years is $-\mathrm{I} \cdot 0 \mathrm{or}$, and significant at the I per cent. level, annual differences being statistically insignificant.

Since sire differences are almost certain to have existed, an analysis of intra-sire relationships between $F$ and production was performed. Briefly, all pullets of a sire were divided into two groups, those of higher and those of lower $F$, and the mean egg production of each group found. In each year, therefore, some sires had offspring with a lower $F$ value having the higher production, while lower $F$-value pullets from other sires had poorer production than their half-sisters. If inbreeding had no effect on egg production, there should be no significant deviation from a I : I ratio between these groups of sires. Table 3 shows the results, the numbers under "lower" and " higher" indicating the numbers of sires in each year for which pullets with higher or pullets with lower $F$ values had the superior production. In 13 years more sire families had superior production amongst the pullets of lower $F$. In three years the reverse was true. In two years (1940 and I948) equal numbers were found. In general, this table shows results comparable to those which might have been anticipated from the actual regression coefficients of table I, column $(b)$. Over all years, pullets from I2 I sires had higher production than their half-sisters with a higher $F$ value; the reverse was true for pullets from 77 sires. The test of significance at the bottom of table 3 shows that the $\chi^{2}$ value for the deviation from a $\mathrm{I}:$ I ratio in all years was $9 \cdot 778$, significant at the I per cent. level. On the other hand, the $\chi^{2}$ value for heterogeneity between years, 19.594 for 17 degrees of freedom, is not statistically significant.

In table 4 regression coefficients of mean production weighted by pullet number per family, together with the pooled weighted regression, are shown for 9 of the years. Since, where an association exists, family size and $F$ appear to be negatively correlated-higher inbreeding being associated with smaller family size-it might be anticipated that a regression weighted by pullet number would show coefficients which were displaced in the negative direction. This is, 
in general, to be seen in table 4. The pooled weighted regression for all 9 years has a coefficient of $-I \cdot I 74$, compared with the pooled unweighted coefficient of $-\mathrm{I} \cdot 0 \mathrm{O}$ for all $\mathrm{I} 8$ years, and reaches significance at the I per cent. level. That annual production is decreased by inbreeding, therefore, appears a valid conclusion.

TABLE 3

Analysis of dam families within sires, as described in the text. $\chi^{2}$ values are for deviation from a $I: I$ ratio

\begin{tabular}{|c|c|c|c|c|}
\hline Year & Lower & Higher & Sires & $x^{2}$ \\
\hline $\begin{array}{l}1932 \\
1933 \\
1934 \\
1935 \\
1936 \\
1937 \\
1938 \\
1939 \\
1940 \\
1941 \\
1942 \\
1943 \\
1944 \\
1945 \\
1946 \\
1947 \\
1948 \\
1949\end{array}$ & $\begin{array}{r}6 \\
8 \\
7 \\
5 \\
8 \\
5 \\
9 \\
10 \\
7 \\
9 \\
3 \\
8 \\
3 \\
6 \\
6 \\
7 \\
6 \\
8\end{array}$ & $\begin{array}{l}5 \\
1 \\
2 \\
3 \\
2 \\
7 \\
3 \\
2 \\
7 \\
3 \\
6 \\
5 \\
7 \\
5 \\
4 \\
4 \\
6 \\
5\end{array}$ & $\begin{array}{r}\text { I I } \\
9 \\
9 \\
8 \\
10 \\
12 \\
12 \\
12 \\
14 \\
12 \\
9 \\
13 \\
10 \\
11 \\
10 \\
11 \\
12 \\
13\end{array}$ & $\begin{array}{l}0 \cdot 091 \\
5 \cdot 444 \\
2 \cdot 778 \\
0 \cdot 500 \\
3 \cdot 600 \\
0 \cdot 333 \\
3 \cdot 000 \\
5 \cdot 333 \\
0 \\
3 \cdot 000 \\
1 \cdot 000 \\
0.692 \\
1.600 \\
0 \cdot 091 \\
0 \cdot 400 \\
0 \cdot 818 \\
0 \\
0 \cdot 6992\end{array}$ \\
\hline All years & I 2 I & 77 & $19^{8}$ & $29 \cdot 372$ \\
\hline
\end{tabular}

\begin{tabular}{|c|c|c|}
\hline & d.f. & $\chi^{2}$ \\
\hline Deviation from I : I ratio & I & $9.778 p<0.01$ \\
\hline Heterogeneity between years & I 7 & 19.594 $p \simeq 0.3$ \\
\hline Total & 18 & $29 \cdot 372$ \\
\hline
\end{tabular}

Table 2, line $(b)$, shows that the coefficients of the pooled unweighted regressions of mean family production on $F$ have increasing negative values for the three consecutive sub-periods: -0.618 from I $932-37,-\mathrm{I} \cdot \mathrm{I} 57$ from $1938-42$, and $-\mathrm{I} \cdot 330$ from $1943-49$. These results suggest that the relationship between production and inbreeding may be better described in a polynomial, rather than a linear, regression. No satisfactory scale transformation could be found to apply with consistency equally well to all years. It seemed preferable, also, to investigate any possible nonlinearity in the relationship of production and $F$ by studying whole generations. Table 5 shows the sums of squares of the linear and quadratic components of mean egg production per family on $F$, for the years $1942-48$, and the " error " mean square for each component. The method used was that described by Mather 
(1949). Of the 7 years investigated, 4 show that the quadratic component removed a greater sum of squares than did the corresponding

TABLE 4

The result of weighting the mean hen-housed family production to Ist October by the number of pullets in the family, and calculating the regression of this weighted production mean on the family F, is shown here for each of several years between 1932 and 1949, together with the pooled regression of all the chosen years combined

\begin{tabular}{|c|c|c|c|c|}
\hline \multirow{2}{*}{ Year } & \multicolumn{2}{|c|}{ Regression } & \multicolumn{2}{|c|}{ Error } \\
\hline & Value & M.S. & d.f. & M.S. \\
\hline $\begin{array}{l}\text { I } 934 \\
\text { I } 936 \\
\text { I } 938 \\
\text { I } 940 \\
\text { I } 943 \\
\text { I } 944 \\
\text { I } 946 \\
\text { I } 947 \\
\text { I } 948\end{array}$ & $\begin{array}{r}-0.525 \\
-2.667 \\
-0.764 \\
-1.100 \\
0.108 \\
1.707 \\
-5.036 \\
-2.236 \\
-2.225\end{array}$ & $\begin{array}{r}1674 \\
42,810 \\
5357 \\
8850 \\
96 \\
\text { I } 3,453 \\
\text { I08,539 } † \\
\text { I } 9,490 \\
\text { I } 1,940\end{array}$ & $\begin{array}{l}94 \\
78 \\
82 \\
77 \\
91 \\
81 \\
89 \\
77 \\
74\end{array}$ & $\begin{array}{r}7911 \\
8008 \\
14,871 \\
15,690 \\
6784 \\
8358 \\
9595 \\
10,795 \\
10,059\end{array}$ \\
\hline \multicolumn{3}{|c|}{$\begin{array}{l}\text { All years : }-\mathrm{I} \cdot \mathrm{I} 74 \\
\text { M.S. for joint regression : } 71,794 \dagger \\
\text { M.S. for differences between regressions : } 17,552\end{array}$} & 743 & IO, 12 I \\
\hline
\end{tabular}

* significant at $P<0.05$

$\dagger$ significant at $P<0.0 \mathrm{I}$

\section{TABLE 5}

The effect of fitting quadratic regression of mean hen-housed family production (to Ist Oct.) on F, for the years 1942-1948. Analysis of both linear and quadratic components arc shown, and the numbers of the degrees of freedom in each case are shown in parentheses

\begin{tabular}{|c|c|c|c|c|}
\hline \multirow{2}{*}{ Year } & \multicolumn{2}{|c|}{ Linear component } & \multicolumn{2}{|c|}{ Quadratic component } \\
\hline & Regression S.S. & Error M.S. & Regression S.S. & Error M.S. \\
\hline $\begin{array}{l}\text { I } 942 \\
\text { I } 943 \\
\text { I } 944 \\
\text { I } 945 \\
\text { I } 946 \\
\text { I } 947 \\
\text { I } 948\end{array}$ & $\begin{array}{r}4707 \\
2842 \\
384 \\
6581 \\
12,783 \\
313 \\
995\end{array} *$ & $\begin{array}{l}224^{8}(72) \\
1993(9 \mathrm{I}) \\
3904(8 \mathrm{I}) \\
2 \mathrm{I} 30(90) \\
3028(89) \\
2609(77) \\
2 \mathrm{I} 66(74)\end{array}$ & $\begin{array}{c}4733 \\
5830 \\
36 \\
784^{6} \\
20,33^{2} \dagger \\
0 \\
929\end{array}$ & $\begin{array}{l}2213(7 \mathrm{I}) \\
1950(90) \\
3953(80) \\
2065(89) \\
2831(88) \\
2678(76) \\
2183(73)\end{array}$ \\
\hline
\end{tabular}

* significant at $P<0.05$

$\dagger$ significant at $P<0.0 \mathrm{I}$

linear component : but only in 1946 did either component reach statistical significance : the linear at the 5 per cent. and the quadratic at the I per cent. levels. 
3. Other measures of production. Table I, column $(c)$, shows the linear regression coefficients of mean family part-production (from first egg to the ist December) on $F$ from I932-49. The means were again based on the initial family size. Only io years have negative coefficients, five of them being in the period $193^{2-36}$. The coefficients are, however, statistically significant in only 3 years : -0.605 in I933 (P<O.OOI) ; - I. I68 in $\mathrm{I} 939(\mathrm{P}<\mathrm{O} \cdot \mathrm{OI}) ;$ and $\mathrm{I} \cdot \mathrm{I} 76$ in 1942 $(\mathbf{P}<0 \cdot 05)$. Table 2, line $(c)$, shows that, from $1932-37$, the pooled regression of -0.335 is statistically significant at the I per cent. level, differences between yearly regressions not reaching significance ; that, from $193^{8}-4^{2}$, the differences between years but not the pooled regression of 0.033 , are significant at the I per cent. level; and that, from 1943-49, neither the pooled regression of 0.037 nor the yearly differences reach statistical significance. The pooled regression for all years is -0.107 and not significant, but the yearly differences are significant $(\mathrm{P}<\mathrm{O} \cdot 05)$.

Analysis of December production itself might yield information about the association of rate of production and pausing, with inbreeding. The coefficients of regression using this measure of production are shown in table $\mathrm{I}$, column $(d)$. Only 3 of the 13 negative coefficients reach statistical significance : -0.265 in 1933 ( $\mathrm{P}<0.00 \mathrm{I})$, -0.353 in $1939(\mathrm{P}<0.01)$ and -0.393 in $1946(\mathrm{P}<0.05)$. One of the 5 positive coefficients, 0.404 in 1942 , is significant at the 5 per cent. level. Table 2, line $(d)$, shows that, from 1932-37, the pooled regression of -0.103 is significant at the 5 per cent. level, yearly differences not reaching significance ; that, from $1938-42$, the pooled regression of -0.080 is not significant, but the yearly differences reach the 5 per cent. level; and that, from I943-49, the regression $(-0 \cdot 098)$ and the yearly differences are, alike, statistically insignificant. The pooled regression coefficient for all years is -0.094 and significant $(\mathrm{P}<\mathrm{O} \cdot \mathrm{OI})$, the differences between years also reaching significance $(\mathrm{P}<0.05)$.

Table I, column $(e)$, shows the yearly coefficients of the linear regression of survivor production on $F$. Survivors were defined as those birds alive on ist July of the initial laying year, and production to that date was used. In some years after I94 I partial culling took place between July and October. These were, in almost every case, sick birds showing abnormalities at autopsy, and might have been expected to die before October; nevertheless, the earlier month of July was chosen, as a criterion for determining a survivor, in order to eliminate bias. In occasional years prior to I 94 I a few birds were culled earlier than July, in order to make room for new stock. Prior to I94I, therefore, no survivor regressions were calculated. Of the 9 years analysed, 7 have negative regressions. The coefficient of - I.976 in 1946 , alone, reaches significance, at the 5 per cent. level. Table 6 , line $(a)$, shows that neither the pooled regression of these years $(-0.4$ I2), nor the yearly differences, are statistically significant. 
4. Production of dead birds. An attempt, shown in table 7, was made to determine whether the birds which died had, on the average,

TABLE 6

The pooled regressions for the years 1941-1949 of (a) family mean survivors' production to Ist 7 uly on F, (b) month of death on F, and (c) production to time of death on $\mathrm{F}$

\begin{tabular}{|c|r|r|r|r|r|r|}
\hline & \multicolumn{2}{|c|}{ Pooled regression } & \multicolumn{2}{|c|}{ Yearly differences } & \multicolumn{2}{|c|}{ Error } \\
\cline { 2 - 7 } & Value & M.S. & d.f. & M.S. & d.f. & M.S. \\
\hline$(a)$ & -0.412 & 1817 & 8 & 1905 & $76 \mathbf{1}$ & 994 \\
$(b)$ & -0.016 & 4 & 8 & 10 & 836 & 12 \\
$(c)$ & 0.025 & 11 & 8 & 1436 & 836 & 4094 \\
\hline
\end{tabular}

higher $F$ values than the mean for the whole of the flock in their generation. For each year from I94I the mean $F$ of all birds dying

TABLE 7

The mean $\mathrm{F}$ of all birds which died before (a) Ist January, and (b) Ist July, compared with the mean $\mathrm{F}$ of the whole flock when each family $\mathrm{F}$ is reeighted by its pullet number

\begin{tabular}{|c|c|c|c|c|c|c|}
\hline \multirow{2}{*}{ Year } & \multicolumn{2}{|c|}{ (a) ist January } & \multicolumn{2}{|c|}{ (b) ist July } & \multicolumn{2}{|c|}{ (c) Whole flock } \\
\hline & No. & $F$ & No. & $F$ & No. & $F$ \\
\hline I 94 I & 37 & I $2 \cdot 303$ & 130 & II 315 & 638 & 10.626 \\
\hline 1942 & 23 & 9.084 & $5^{8}$ & $9 \cdot 076$ & 424 & 9.101 \\
\hline 1943 & $3^{I}$ & $10.33^{8}$ & 104 & I I- 779 & 650 & I I 737 \\
\hline 1944 & 9 & I $2 \cdot 33^{8}$ & 49 & 11716 & 260 & 12.367 \\
\hline 1945 & 30 & ${ }^{1} 3.001$ & 98 & 13.901 & 445 & 13.398 \\
\hline 1946 & 32 & I $5 \cdot 106$ & $6 I$ & 14.464 & 479 & 14.008 \\
\hline 1947 & 43 & 14.013 & 107 & 13.891 & 474 & $13 \cdot 838$ \\
\hline $194^{8}$ & 30 & 14.426 & 86 & 14.207 & 549 & 14.433 \\
\hline I 949 & 63 & I $5 \cdot 8$ I 9 & I $6 I$ & $16 \cdot 15^{8}$ & 617 & 15.860 \\
\hline All years & 298 & 13.426 & 854 & 13.291 & $453^{6}$ & $12 \cdot 880$ \\
\hline
\end{tabular}

before $(a)$ ist January, and $(b)$ ist July, are compared with the flock mean, the latter obtained by weighting each family $F$ by the initial family size. If inbreeding contributes to increased mortality, the mean $F$ of $(a)$ should be higher than for $(b)$, and both higher than the flock mean. Only three years (I94I, I946 and I947), however, show this trend, although 6 years show an $F$ of birds dying before July which is greater than that for the whole flock. Combining all dead birds in all years, the $F$ of birds dying before January is 13.426 , before July is $13.29 \mathrm{I}$, and for the flock in all years, I 2.880 , suggesting that inbreeding is accompanied by higher death rate and also by earlier age at death. 
To compute regressions of month of death of dead birds on $F$, each month was numbered in sequence. Table $\mathrm{I}$, column $(f)$, shows the linear regression coefficient of month of death of dead birds on the $F$ of the family of which each bird was a sister. Six of the 9 years from I94 I-49 have negative regression values, none reaching statistical significance. Table 6 , line $(b)$, shows the pooled analysis for all 9 years. Neither the pooled coefficient $(-0 \cdot 016)$ nor the differences between years, are statistically significant.

TABI.E 8

Within-year analyses of profiortions of deaths betiven unit differences of $\mathrm{F}$ (see text). The table shows, for each year from $1.941-1.949$ and for 1955 , the regression of proportion of dead birds in families on the fomily $\mathrm{F}$ unit group, and the significance of the heterogeneity between proportions

\begin{tabular}{|c|c|c|c|c|}
\hline \multirow{2}{*}{ Year } & \multicolumn{2}{|c|}{ Regression } & \multicolumn{2}{|c|}{ Heterogeneity } \\
\hline & Value & M.S. & d.f. & S.S. \\
\hline I94I & $0.0069 *$ & 0.895 & I 9 & $9 \cdot 634 \div$ \\
\hline 1942 & -0.0067 & 0.165 & I 2 & $2 \cdot 698$ \\
\hline 1943 & -0.0057 & 0.263 & I5 & $4 \cdot 546$ \\
\hline I 944 & -0.0066 & 0.205 & 15 & $2 \cdot 392$ \\
\hline 1945 & 0.0045 & 0.183 & I 7 & $4 \cdot 330$ \\
\hline $194^{6}$ & 0.0078 & $0 \cdot 308$ & 14 & $2 \cdot 059$ \\
\hline 1947 & 0.0078 & $0 \cdot 242$ & I 2 & I $\cdot 989$ \\
\hline $194^{8}$ & 0.0023 & 0.013 & Io & $2 \cdot 79 \mathrm{I}+$ \\
\hline 1949 & 0.0039 & 0.106 & I 4 & $6.991 \dagger$ \\
\hline 1955 & -0.0027 & 0.028 & 7 & $5.019 \ddagger$ \\
\hline
\end{tabular}

* significance at $P<0.05$

$\dagger$ significance at $P<0^{\circ} \mathrm{OI}$

\pm significance at $P<0 \cdot 00$ I

Table I, column $(g)$, gives the yearly coefficient of the regressions of production to time of death of dead birds, on $F$. Six years show -negative coefficients, none reaching statistical significance. Table 6, line $(c)$, shows the pooled analysis for the 9 years. Neither the pooled regression coefficient $\left(\mathrm{O}^{\circ} \mathrm{O} 25\right)$, nor the yearly differences, reach significant levels.

Lastly, an attempt to determine whether families of higher inbreeding contained, on the average, a greater number of birds dying beforre July is summarised in table 8 . The method outlined by Armitage ( 1955$)$ was used, the essential question asked being whether or not the proportion of birds dying within each year showed a significant trend with the increase of the family inbreeding value. In each year families were gr - uped in unit percentage differences of $F$ : for example, all families in I 94 I the $F$ of which was between 7.000 and 7.999 are pooled, and give a total of 24 deaths from an initial pullet number of 78 , or a mortality proportion of 0.308 and an $F$ of 7.500 . A linear regression of this proportion on $F$ can then be found, together with 
the significance of the heterogeneity present. As shown, 6 of the 9 years have positive coefficients (suggesting that the proportion of deaths increases with an increasing $F$ ), only that for I94 I (o.0o69) reaching the 5 per cent. level of statistical significance. Furthermore, heterogeneity is highly significant in I94I ( $\mathrm{P}<\mathrm{O}^{\circ}$.0OI) and in 1949 $(\mathrm{P}<\mathrm{O} \cdot \mathrm{OI})$. The value for 1955 was also computed in order to see if the positive regressions of the years $1945-49$ are maintained : but the coefficient is negative and insignificant, heterogeneity in that year being highly significant $(\mathrm{P}<\mathrm{O} \cdot \mathrm{OOI})$.

\section{DISCUSSION AND CONCLUSIONS}

The factors determining total number of offspring reaching reproductive age are known to be numerous and include the number, fertility and hatchability of eggs, and rearing viability. At least some of these components of fitness may be adversely affected by inbreeding. Düzgüneş (1950) found that, in general, in the intensely inbred lines which he analysed, inbreeding tended to reduce the numbers of offspring which survived to breeding age, largely as a result of decreased hatchability, although other characters were also affected to some extent. If, however, as in this report, female offspring alone are considered, additional variance will be introduced by chance deriations in the sex ratio. Since, therefore, the pooled regression of family size (pullets only) on $F$ in all years is statistically significant (table 2), inbreeding effects appear to have been pronounced enough to be demonstrable in spite of this chance variation in sex. When the period is broken down into 3 sub-periods only the first 2 of these show pooled significance. It seems reasonable to explain the absence of significant trends during the last sub-period as being due to the more restricted range of $F$ values in these years (table I). In other words, it is probable that in earlier years the range of inbreeding was great enough for inbreeding effect on pullet number to be revealed in spite of deviations in the sex ratio; in later years the range became too narrow, and chance was the chief determinant.

The analyses reported here clearly show that inbreeding has had a detrimental effect on production within generations. Lerner and Hazel (I947) have previously calculated the regressions of mean family production on the computed $F$ for 4 years of this flock. In doing so, they excluded all families of less than 5 pullets, and obtained coefficients of $-0.54,-0 \cdot 46,-5 \cdot 8$ I and 0.84 for 1935, I 937, I 939 and I94I, respectively, of which only the I 939 figure was statistically significant. The coefficients of table I for these years are, in order, $-0.964,0.276,-5.109$ and $-\mathrm{I} \cdot 2 \mathrm{II}$, the I 939 figure again being the only one of significance. The average for the four years of Lerner and Hazel was $-\mathrm{I} \cdot 20$, and this was statistically insignificant. The authors, therefore, concluded that there appeared to be insufficient evidence to suggest that inbreeding was important in limiting production. The more extensive analyses of this report justify the conclusion 
that a linear regression of about one egg for every per cent. increase in computed $F$ can be detected in the means of family production. This rate, incidentally, is very similar to those reported for mixed inbred lines by others. Shoffner (1948) for example, found the withinsire regression of full-sister mean family production on the mean inbreeding value to be -0.926 .

Mean egg production of dam families, taken to October of the first laying year and based on the initial pullet numbers per family is, of course, a composite figure. Several or all of the following may occur :

I. rate of production may be higher in less inbred birds than it is in birds of greater inbreeding;

2. birds of lower levels of inbreeding may reach sexual maturity earlier than do birds of higher inbreeding levels ;

3. the proportion of deaths may be higher amongst birds of greater inbreeding levels than amongst those of lower levels;

4. deaths amongst birds of higher inbreeding levels may be earlier than those amongst lower levels, so that the former group lay fewer eggs than the latter;

5. the rate of production of dead birds may be higher amongst birds of lower inbreeding levels than amongst those of higher ;

6. there may be a complex interaction of all or some of these factors.

The bottom line of table 2 shows an overall significant regression of mean family December production on $F$ and, at the same time, significant differences between years. December egg production includes, of course, not only rate of lay when in lay but also the effect of possible winter pausing. That yearly differences are significant can possibly be a reflection of climatic conditions : when production drops due to unfavourable conditions, more highly inbred birds may be affected the most; when the season is less severe laying may be less subject to effect by inbreeding. A longer period of time, such as the whole year, may contain successive sub-periods of unfavourable, favourable and indifferent climatic conditions, and analyses of this longer period may be obscured by the changes in conditions it embraces, while yearly differences in these analyses may be further obscured. It is possible, therefore, that within a smaller interval of time, such as December, climatic conditions may determine much of the year-toyear differences encountered. In other words, rate of lay when birds are laying may be but little affected by inbreeding, whilst the tendency to react to bad seasonal effects by pausing may be largely determined by inbreeding level, the more highly inbred birds pausing first. Further work is, however, necessary to verify this. At the same time, the December regression of all years combined is itself highly significant in table 2, and gives grounds for thinking that inbreeding has also an influence directly on rate of production during this month. 
Inbreeding, in view of the insignificant pooled coefficients of regression to December in table 2, would appear to have little effect on sexual maturity. There was, however, a highly significant regression for the pooled analysis of the first sub-period, 1932-37. An explanation could be that, in earlier years the wider range of $F$ values revealed inbreeding effects during these years; though there are many further complications in this character (e.g. the effect of date of hatch).

The suggestion in table 7 , that more and earlier deaths occur amongst birds of higher inbreeding levels than amongst those of lower, is not statistically established by the analyses reported in tables 6 and 8 , nor is the relationship between the production of either surviving birds or birds dying in the course of the year and the $F$ values statistically significant.

Hence, although there is ample evidence that inbreeding affects egg production when the latter is measured as a hen-housed average, the precise manner in which it does so is not clearly apparent. It is interesting that, in all calculations, there are indications of the detrimental effect of inbreeding, even though these indications rarely reach statistical significance. The majority of years show negative regression coefficients for nearly all traits examined, with the exception of table 8 , where in this case the detrimental effects of inbreeding would be revealed by positive signs for the coefficients of regression. There is, therefore, an underlying consistency in the results, and much yearly difference. The underlying consistency may be spurious, but both this and the yearly heterogeneity point to the same tentative conclusion. This conclusion, which requires further work before validation, is that inbreeding has an overall debilitating effect on nearly every factor contributing to production, but chiefly that it carries a penalty in times of stress.

A consequence resulting from the adverse effects of inbreeding on production is that the birds selected from a given generation are likely to be in the lower range of $F$ values for that generation, and the unselected birds in the higher. To test this, a short survey was made of the years 1943, 1944, 1945 and 1946, the results being as follows :

\begin{tabular}{|c|c|c|c|c|c|}
\hline \multirow{2}{*}{ Hatch } & \multicolumn{2}{|c|}{ Unselected pullets } & \multicolumn{2}{|c|}{ Sclected pullets } & \multirow{2}{*}{ Mating } \\
\hline & No. & $\bar{F}$ & No. & $\bar{F}$ & \\
\hline 1943 & $5^{83}$ & 12.211 & 67 & I $2 \cdot 495$ & 1945 \\
\hline 1944 & 202 & I $2 \cdot 375$ & $5^{8 *}$ & I $2 \cdot 33^{8}$ & $194^{6}$ \\
\hline 1945 & 377 & I $349^{8}$ & 68 & I 2.845 & I 947 \\
\hline $194^{6}$ & $4^{0} 4$ & 14.154 & 77 & I3. I99 & I $94^{8}$ \\
\hline
\end{tabular}

* This figure differs from that in 1944 reported by Lerner and Dempster (I95I) in their table 4 . because of 16 birds included in their report for which the inbreeding coefficients were not available.

In 3 of the 4 years the $F$ of selected pullets is slightly less than that for unselected sisters. 
There are two possibilities which should also not be overlooked in examining the results reported. The first of these is that linear regression may not be adequate to describe the relationship of inbreeding and factors contributing to production. The results of table 5 are far from conclusive. Yet Stephenson et al. (1953) reached the decision that in their material the regression did not become linear until the $F$ value had reached 25 per cent., although they were concerned specifically with cgg production rate and their lines were more rapidly inbred. Secondly, the differences between the actual increases in homozygosity and the computed $F$ value may not be proportionally the same throughout the period studied.

\section{SUMMARY}

I. A S.C.W. Leghorn flock of the University of California has been subject to continuous selection for egg production since 1932. Inbreeding increases, however, have been kept at a minimum consistent with the size of the flock and the selection pressure exercised.

2. Intra-generation regressions of mean family production to the start of October in the first laying year on the computed $F$ values, for each of the years 1932-49, have mostly negative coefficients. Coefficients of only 2 of the 18 years reached statistical significance but the pooled regression for the total period showed a highly significant negative coefficient of about one egg for every per cent. increase in the computed $F$.

3. Family size, when pullets alone are considered, appeared to be correlated with the family $F$ value prior to i 942 , but uncorrelated in later years. It is suggested that, in later years, the narrower range of $F$ values, and chance deviations in the sex ratio, contributed to remove any real effect of inbreeding on family size. There was a statistically significant negative regression coefficient of -0.047 pullets for every increase in per cent. $F$, when all years were combined.

4. Within-sire analyses corroborated the presence of an adverse effect of inbreeding on production.

5. Quadratic regression does not, in the data analysed, appear to be a closer description of the relationship between production and inbreeding, possibly due to the large amount of yearly heterogeneity present.

6. No significant regressions of survivors' production, month of death and production to death of dead birds, or per cent. viability on $F$, were observed. It can be shown, however, that over all years, the mean $F$ of birds dying was slightly greater than that of birds surviving, and that the mean $F$ of birds dying earlier was slightly greater than that of birds dying later.

7. It is concluded that, although even slow inbreeding detrimentally affects the hen-housed production within any year, the precise manner in which it does so is not clearly apparent. An underlying consistency 
in the material investigated is accompanied by yearly heterogeneity. Inbreeding probably affects adversely nearly every factor contributing to total production. It is suggested that its severest consequences are found when environmental and local conditions create situations involving stress.

Acknowledgments.-I wish to record my appreciation of the help and encouragement freely extended by Professor I. M. Lerner and Mrs Dorothy Lowry of the Department of Poultry Husbandry, and by Professor E. R. Dempster of the Department of Genetics, in the University of California, Berkeley.

\section{REFERENCES}

ARmitaGe, P. 1955. Tests for linear trends in proportions and frequencies. Biometrics, 2, 375-386.

DÜZGÜNEŞ, o. 1950. The effect of inbreeding on reproductive fitness of S.C.W. Leghorns. Poultry Science, 29, 227-235.

JULL, M. A. 1933. Inbreeding and intercrossing in poultry. 7. Hered., 24, 93-100.

LERNer, I. M. I950. Population Genetics and Animal Improvement. C.U.P., Cambridge.

LERNER, I. M., AND DEMPSTER, E. R. I95I. Attenuation of genetic progress under continued selection in poultry. Heredity, 5, 75-94.

LERNER, I. M., AND HAZEL, L. N. I947. Population genetics of a poultry flock under artificial selection. Genetics, 32, 325-339.

MATHer, K. 1949. Statistical Analysis in Biology. Methuen, London.

Shoffner, R. N. 1948. The reaction of the fowl to inbreeding. Poultry Science, 27, $44^{8-452 .}$

STEPHENSON, A. B., WYATT, A. J., AND NORDSKOG, A. W. 1953. Influence of inbreeding on egg production in the domestic fowl. Poultry Science, 32, 5 10-517. TEBB, G. 1957. Inbreeding effects contrary to the direction of selection in a poultry flock. Poultry Science, 36, 402-405. 